\title{
Turkish Adaptation and Reliability and Validity Study of Parent Attitudes About Childhood Vaccines Survey
}

\author{
(D) Mehtap Ataseven Bulun1, (1) Deniz Acuner² \\ 1'istanbul Okan University, Vocational School of Health Services, İstanbul, Turkey \\ ¿Üsküdar University Faculty of Medicine, Department of Health Management, İstanbul, Turkey
}

\begin{abstract}
Aim: Since the discovery of vaccines, opposing views have emerged and spread to the present day. Despite being based on different beliefs in different societies, anti-vaccination has become a rapidly growing social movement worldwide. Resistance to vaccination was included among health hazards at a global level by the World Health Organization in 2019. In a review of the literature, some studies conducted on vaccine rejection, vaccine hesitations and vaccine acceptance were found in different countries, but no studies in which vaccine hesitation was examined had been conducted in Turkey. The main reason was considered to be the lack of a vaccine attitude scale adapted into the Turkish language.

The aim of this study was to carry out a vaccination attitudes scale validity and reliability test on a scale which had been proven in foreign empirical studies and been translated into the Turkish language and to publish the scale in the field literature to be used in future vaccination attitudes studies in Turkey.
\end{abstract}

Materials and Methods: This study is a methodological study. The Parent Attitudes about Childhood Vaccines (PACV) scale was translated into Turkish by three experts who were competent in both English and Turkish, then it was translated back into English again. As a result of the comparison made, several changes were made to the Turkish scale. A pilot application was used and its results were evaluated. Confirming the results of the pilot application, the scale was applied to 225 parents. The reliability of the analyzed data was tested via Cronbach's alpha.

Results: The reliability of the data was determined to be $\mathbf{0 . 8 4}$, and the scale was considered reliable. Confirmatory factor analysis for the adapted scale was carried out, and the adaptation of the scale into Turkish was completed.

Conclusion: The Turkish version of the PACV scale is a valid and reliable scale for evaluating vaccine attitudes including vaccine rejection, vaccine hesitations and vaccine acceptance.

Keywords: Anti-vaccination movement, vaccination refusal, reliability and validity, questionnaires

\section{Introduction}

Vaccination is one of the most effective methods to protect against infectious diseases and maintain health. Starting from infancy, vaccination is an important factor for healthy growth and development. Despite its effectiveness and safety proven by scientific studies, anti-vaccination opinions have become widespread in society nowadays (1). Although the growth of the anti-vaccination as a social movement all around the world is fed with some common beliefs, the development of anti-vaccination attitudes in parents can happen as a result of different dynamics (2). Today, the 'Strategic Advisory Group of Experts' (SAGE) 
meetings are held by the World Health Organization with regard to these rapidly growing anti-vaccine movements (3). In a report prepared by SAGE, the reasons for antivaccination are mainly grouped under three titles. These were classified as contextual effects, individual and group effects, and also specific subjects related to vaccine/ vaccination (4). The causes of anti-vaccination trends are shown in Table I.

With the proliferation of anti-vaccination movements, adherence to vaccination schedules and immunization rates have begun to decline in many countries and the number of cases of some infectious diseases, which were close to elimination, have increased. The main obstacle to the implementation of vaccination programs is regarded as the fact that some families have doubts or direct resistance to the vaccination calendar (5).

Hagood and Herlihy (6) defined the classification of parents experiencing anxiety about vaccination into three groups. The first group is vaccine rejectors (VRJ) who strongly reject vaccination. The second group include vaccine resistants who are more willing to assess the safety and efficacy of vaccines than VRJ although they still refuse vaccination. The third parent group is made of people who have some hesitancy about some vaccines and are generally concerned about vaccinations.

Although anti-vaccination is the main concept which is emphasized in maintaining social immunity, recently vaccination hesitancy, which is the invisible part of the iceberg, has been more controversial (7). According to Dubé et al. (8), the concept of "vaccine hesitation", which was introduced in response to an inability to consider attitudes and behaviors towards vaccination as just "acceptance" or "rejection", defines doubts about vaccination resulting in delays in vaccination schedules and rejection although it is provided as a service. Since the concept covers individuals who reject vaccination and those who have doubts, it offers a more holistic approach.

In studies conducted so far, it has been determined that some important reasons for hesitation against vaccinations include concerns about the safety of vaccinations, perception that vaccinations are not beneficial, fear of injections or insecurities about the implementation of vaccination programs and towards the pharmaceutical industry (9-11). In a study conducted in Turkey, similar results were obtained, and it was determined that parents' hesitations about vaccines included concerns about the contents of vaccines and the side effects of vaccinations, the inability to obtain adequate information about vaccines, religious beliefs, mistrust of the pharmaceutical industry and the probable relations of interest between the industry and authorities (12).

It is important to determine those people who are hesitant about vaccination primarily in the planning of interventions concerning vaccine hesitation. Although SAGE

\begin{tabular}{|c|c|c|}
\hline Contextual effects & Individual and group effects & Vaccine and vaccination specific issues \\
\hline $\begin{array}{l}\text { a. Communication and media } \\
\text { environment }\end{array}$ & $\begin{array}{l}\text { a. Personal, family and/or community } \\
\text { members' experiences related to } \\
\text { vaccines including pain }\end{array}$ & $\begin{array}{l}\text { a. Risk/benefit (epidemiological and } \\
\text { scientific evidence) }\end{array}$ \\
\hline $\begin{array}{l}\text { b. Effective leaders, vaccination program } \\
\text { guardians and anti-vaccination or } \\
\text { vaccination lobbies }\end{array}$ & $\begin{array}{l}\text { b. Attitudes towards beliefs, health and } \\
\text { protection }\end{array}$ & $\begin{array}{l}\text { b. Applying a new vaccine or a new } \\
\text { formulation or a new recommendation for } \\
\text { an existing vaccine }\end{array}$ \\
\hline c. Historical influences & c. Knowledge/awareness & c. Management mode \\
\hline $\begin{array}{l}\text { d. Religion/culture/gender/ } \\
\text { socioeconomic }\end{array}$ & $\begin{array}{l}\text { d. Health system and providers-trust and } \\
\text { personal experience }\end{array}$ & $\begin{array}{l}\text { d. Design of vaccination program/delivery } \\
\text { method (e.g. routine program or mass } \\
\text { vaccination campaign) }\end{array}$ \\
\hline e. Politics/policies & e. Risk/benefit (perceived, intuitive) & $\begin{array}{l}\text { e. Reliability and/or supply of vaccine and/ } \\
\text { or vaccination equipment }\end{array}$ \\
\hline f. Geographical barriers & $\begin{array}{l}\text { f. Immunization as a social norm/not } \\
\text { required/harmful }\end{array}$ & f. Vaccination program \\
\hline $\begin{array}{l}\text { g. Perception of the pharmaceutical } \\
\text { industry }\end{array}$ & - & g. Costs \\
\hline- & - & $\begin{array}{l}\text { h. The strength of advice and/or knowledge } \\
\text { base and/or attitude of healthcare } \\
\text { professionals }\end{array}$ \\
\hline
\end{tabular}


has prepared several different types of questions to measure vaccine hesitation (13), a uniform and Clobal scale has not been prepared for this purpose. Many different surveys and questionnaires have been used in cross-section studies in different countries to measure parental attitudes towards vaccination (14-19). Many of these questionnaires have focused on a limited number of factors affecting vaccine hesitation, and the reliability and validity of these scales have not been tested. In this context, the Parent Attitudes about Childhood Vaccines (PACV) scale, developed by Opel et al. $(5,20)$ and tested for validity-reliability, is one of the first vaccination hesitation scales. Consequently, the scale has been used in different country-based studies such as in Spain, Canada, Malaysia, Italy, and Iraq (21-27).

In the literature review conducted, a Vaccine Hesitation scale study for a Turkish adaptation was not found. The purpose of this study is to adapt the PACV scale developed by Opel et al. (20) in 2011, which measures parents' hesitations towards childhood vaccination, into the Turkish language and to apply a validity/reliability study on this scale so that the above mentioned gap in the literature is eliminated.

\section{Materials and Methods}

This section describes the implementation processes of the adaptation of the scale and the analyses of its validity and reliability.

\section{Data Collection Tool}

During the development process of the PACV scale, a literature-assisted question pool was created, interviews were made with a focus group, expert opinions on scale items were obtained, and a preliminary test was conducted on a working group of parents. As a result of this process, an 18-item scale was created (5). The Developed scale was evaluated in terms of validity and reliability by applying it to the parents of children of 19 to 35-month-old children in another study. The final form of the scale consisted of 15 items in three sub-dimensions, namely, safety effectiveness, general attitudes and behavior (20). A validation study was conducted to determine the level of accuracy in terms of prediction of the PACV scale on parents' future vaccination behaviors. This study demonstrated the prediction validity and test-retest reliability of PACV (28).

Answers on scale questions were taken from three different response formats including closed-ended (Yes/ No/I don't know), 5-item Likert type (Strongly Agree/Agree/ Not Sure/Disagree/Strongly Disagree) and the scoring type (from 0 to 10). While using scoring scale items, hesitant responses were scored as 2 , unstable responses were scored as 1, unhesitant responses were scored as 0 , and points taken from each item were added without any weighting to determine the total score. A simple linear conversion table was used for the missing data. The lowest score that can be achieved in the scale is 0 and The highest score is 100 (100 points indicate high vaccination hesitation).

\section{Translation Study}

In this study, a "back translation" method was used as one of the scale translation techniques. Beaton et al. (29) suggested that the original scale should be translated by two independent translators and a third translator retranslates the translated scale back into its original language.

To adapt and use PACV, Opel, who is the original developer of the scale, was contacted by email and his written approval was obtained. The PACV scale was translated from English to Turkish by three people who are competent in both languages. Then, their translations were revised and edited by the researchers, and a common translation text was created. This translation of the scale in Turkish was then retranslated into English by a different translator. For PACV, the opinions of four academics in the health field were taken. Experts were asked to give each item a rating between 1 and 4 ( $1=$ Not Applicable, 4= Completely Appropriate) to evaluate the original version and translation of the scale and to assess language/expression suitability and content appropriateness. Based on these experts' assessments, no item was removed from the scale. The final version of the translation, which was created as a result of the experts' assessments, was prepared for use in the study by consulting a linguist who specializes in the Turkish language.

The scale was applied to 30 parents who had similar characteristics with the sample group but would not be included in the pilot study. After this stage, feedback was received from each parent in order to find which of the scale items were understandable and which were difficult to understand. Parents gave feedback mostly on the sixth item of the scale and expressed that this item was unclear or hard to understand. By considering the recommendations of the parents, the scale was given its final form.

\section{Collection of Data}

This study was conducted in the children's services and polyclinics of a private university hospital between January and February 2019. The criteria for inclusion in the study were determined as having a child under 6 years of age and an education level of being at least literate, and these 
criteria were used in the selection of the sample. Written consent forms were taken from each participant. The scale forms were handed over to parents, and they were asked to deliver them after they finished answering these surveys. Completing the scale took the parents an average of 5 minutes.

\section{Statistical Analysis}

To adapt the PACV into the Turkish language, confirmatory factor analysis was conducted to determine accuracy of the three-dimensional structure developed previously by Opel et al. (20). Before the analysis, scale items with different ratings were scored between 0 and 2 points, as in the original, and factor analysis was performed through this scoring. The robust maximum likelihood estimation method was used based on the asymptotic covariance matrix when performing confirmatory factor analysis. Confirmatory factor analysis was carried out with the LISREL 8.80 program. Cronbach's alpha and McDonald's Omega reliability coefficients were calculated to determine the reliability of the measurements obtained. Jamovi (Version 0.9.5.12) (Computer Software) (https://www. jamovi.org) was used to calculate the reliability coefficient.

\section{Ethics Committee Approval}

Ethics Committee approval was given to the study at the $102^{\text {nd }}$ meeting held by Istanbul Okan University Ethics Committee on 09.01.2019 (decision no: 11).

\section{Results}

The study group consisted of 242 parents with a mean age of 36.22 years, ranging from 20 to 56 years old. The descriptive characteristics of the participants are given in Table II.

Analyzing Table II, it can be seen that $90.1 \%$ of respondents $(n=218)$ were mothers, and $9.9 \%$ of them $(n=24)$ were fathers. It was determined that the ratio of parents who have a single child was $49.6 \%(n=120)$; the ratio of parents having two children was $42.1 \%(n=102)$; the ratio of parents having three children was $7 \%(n=17)$; and the ratio of parents having four or more children was $1.2 \%(n=3)$. It was determined that $12 \%$ of the participants $(n=29)$ were 20 to 29 years old, and $87.6 \%$ of them $(n=212)$ were 30 years old or older. Analyzing in terms of educational background, it was found that the majority of participants were holders of a bachelor's degree $(n=117,48.3 \%)$ or postgraduate degree $(n=52,21.5 \%)$ degree. $14.5 \%$ of the study group $(n=35)$ consisted of participants whose income was less than their expenses; $26.4 \% \quad(n=64)$ consisted of participants whose income was more than their expenses; and $58.7 \%$ of them $(n=143)$ consisted of participants whose income was equal to their expenses.

In the confirmatory factor analysis conducted to examine the three sub-dimensions of the PACV scale, conformity of the model data was assessed by examining the conformity index values, factor load values and error variances. Conformity index values, factor load values [maximum (max)- minimum (min)] and error variance (maxmin) values are presented in Table III; and the measurement model acquired as a result of this analysis is presented in Figure 1.

When Table III is examined, it is seen that the value is less than 3, thus, the model can be said to be very well adapted to the data. The comparative fit index value was found to be 0.97, and the Normed Fit index value was determined to be 0.95 . The fact that these values were over 0.90 indicates that the model is perfectly adapted to the data. Since the goodness of fit index value was 0.71 and this value was under 0.90 , it means that there was no adaptation

Table II. Descriptive statistics related to demographic characteristics of participants

\begin{tabular}{|c|c|c|c|c|c|c|c|}
\hline & & $f$ & $\%$ & & & $f$ & $\%$ \\
\hline \multirow{2}{*}{ Parent } & Mother & 218 & 90.1 & \multirow{5}{*}{$\begin{array}{l}\text { Educational } \\
\text { Background }\end{array}$} & Primary school/Primary education & 8 & 3.3 \\
\hline & Father & 24 & 9.9 & & High school & 35 & 14.5 \\
\hline \multirow{4}{*}{$\begin{array}{l}\text { Number } \\
\text { of } \\
\text { Children }\end{array}$} & 1 & 120 & 49.6 & & Undergraduate & 30 & 12.4 \\
\hline & 2 & 102 & 42.1 & & Bachelor's degree & 117 & 48.3 \\
\hline & 3 & 17 & 7.0 & & Postgraduate & 52 & 21.5 \\
\hline & 4 and more & 3 & 1.2 & \multirow{4}{*}{$\begin{array}{l}\text { Economic } \\
\text { Situation }\end{array}$} & My income is less than my expenses & 35 & 14.5 \\
\hline \multirow{3}{*}{ Age } & 20-29 years & 29 & 12.0 & & My income is more than my expenses & 64 & 26.4 \\
\hline & 30 years old and more & 212 & 87.6 & & My income is equal to my expenses & 143 & 58.7 \\
\hline & Have not specified & 1 & 0.4 & & Have not specified & 1 & 0.4 \\
\hline
\end{tabular}


between the data and the model according to this index. The root mean error of approximation index is 0.080 for the model, and it is possible to say that the model showed adaptation to the data when it is evaluated according to this index. The general analysis of the adaptation indices shows that the three-dimensional model was adapted well to the data. Factor load values for items in each dimension varied between 0.35 and 0.91 . Since the factor load values were over 0.30, it can be said that each item serves its purpose in its dimension.

Descriptive statistics and factor load values for answers given to each item in the PACV scale are presented in Table IV.

Cronbach's Alpha and McDonald's Omega Coefficients were used to examine the reliability of the scores acquired

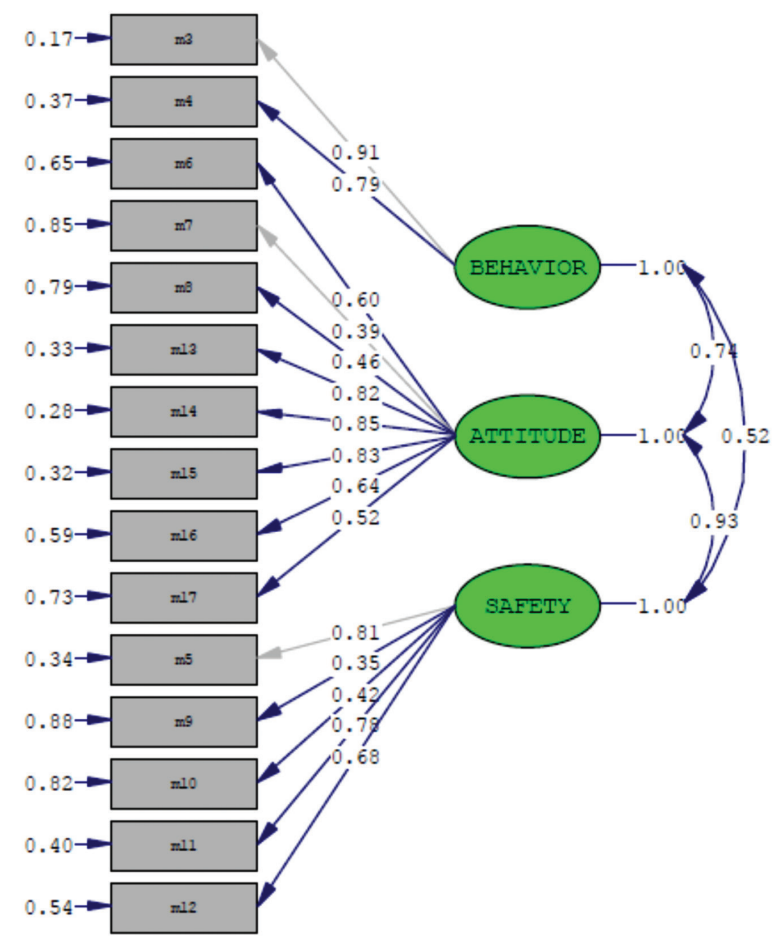

Chi-Square $=221.67, \mathrm{df}=87, \mathrm{p}$-value $=0.0000, \mathrm{RMSEA}=0.080$

Figure 1. Measurement model of parent attitudes about childhood vaccines scale from PACV used within the scope of this study. These findings are presented in Table $\mathrm{V}$.

When examining Table $V$, it can be seen that the reliability values for the scores of the scales used in the study varied between 0.61 and 0.85. Based on the calculated confidence index values, it can be said that the scores obtained from the scale in general are reliable.

\section{Discussion}

The determination of hesitations about immunization and vaccination in the community is very important in planning necessary interventions. At the same time, measurement tools are also needed to determine the effectiveness of interventions.

In this study, the PACV scale was adapted into the Turkish language, applied to 242 parents, and its validity and reliability were determined. According to the results of our analysis, the 15 items on the original scale were preserved on the Turkish scale. According to the results of the factor analysis, it was determined that the Turkish scale was also in a three-factor structure as was the original scale. The Cronbach's alpha coefficients of the original scale had an internal consistency ranging from 0.74 to 0.84 . The Cronbach's alpha reliability value of the Turkish scale was determined to be 0.84 .

The determination of attitudes and hesitations towards vaccinations was not one of the main objectives of this study. However, this study yielded results regarding parents' attitudes towards childhood vaccinations. The absence of published data concerning parents' hesitations towards vaccinations in Turkey has made these results significant. $11.6 \%$ of the parents who participated in this study reported that they decided not to vaccinate their children without any exemptions. In a similar study conducted in North America, the parents' rate of declining one or more vaccines was found to be $15 \%$ (30). Another important conclusion revealed in this study is that $28.1 \%$ of parents describe themselves as hesitant about childhood vaccinations. In a study conducted in the United States, this rate was found

Table III. Confirmatory factor analysis results of parent attitudes about childhood vaccines scale

\begin{tabular}{|c|c|c|c|c|c|c|c|c|c|c|c|}
\hline & & & \multirow[t]{2}{*}{ p } & \multirow[t]{2}{*}{ CFI } & \multirow[t]{2}{*}{ GFI } & \multirow[t]{2}{*}{ NFI } & \multirow[t]{2}{*}{ RMSEA } & \multicolumn{2}{|c|}{$\begin{array}{l}\text { Factor Load } \\
\text { Values }\end{array}$} & \multicolumn{2}{|c|}{ Error Variances } \\
\hline & & & & & & & & $\max$ & $\min$ & $\max$ & $\min$ \\
\hline Scale & 221.67 & 2.55 & 0.000 & 0.97 & 0.71 & 0.95 & 0.080 & 0.91 & 0.35 & 0.88 & 0.17 \\
\hline Recommended Value & & $\chi 2 / d f \leq 3$ & & $\geq 0.90$ & $\geq 0.90$ & $\geq 0.90$ & $\leq 0.080$ & \multicolumn{2}{|c|}{$\geq 0.30$} & \multicolumn{2}{|l|}{$\leq 0.90$} \\
\hline
\end{tabular}

Max: Maximum, min: Minimum, $\chi 2$ : Chi square index, CFI: Comparative fit index, GFI: Goodness of fit index, NFI: Normed fit index, RMSEA: Root mean square error of approximation 
Table IV. Descriptive statistics and factor loads of parent attitudes about childhood vaccines scale

\begin{tabular}{|c|c|c|c|c|c|}
\hline & & \multirow[t]{2}{*}{ n (\%) } & \multicolumn{3}{|c|}{ Factor Load Values } \\
\hline & & & $\begin{array}{l}\text { Safety \& } \\
\text { effectiveness }\end{array}$ & $\begin{array}{l}\text { General } \\
\text { attitudes }\end{array}$ & Behavior \\
\hline \multirow{3}{*}{$\begin{array}{l}\text { 3. Have you ever delayed having your child get a shot } \\
\text { without any risks of illness or allergy? }\end{array}$} & Yes & $14(5.8)$ & & & \multirow{3}{*}{0.91} \\
\hline & No & $228(94.2)$ & & & \\
\hline & Don't know & & & & \\
\hline \multirow{3}{*}{$\begin{array}{l}\text { 4. Have you ever delayed having your child get a shot } \\
\text { (not including seasonal flu or swine flu (H1N1) shots) } \\
\text { for reasons other than illness or allergy? }\end{array}$} & Yes & $28(11.6)$ & & & \multirow{3}{*}{0.79} \\
\hline & No & $213(88.0)$ & & & \\
\hline & Don't know & $1(0.4)$ & & & \\
\hline \multirow{3}{*}{$\begin{array}{l}\text { 5. How sure are you that following the recommended } \\
\text { shot schedule is a good idea for your child? }\end{array}$} & $0-5^{*}$ & $37(15.3)$ & \multirow{3}{*}{0.81} & & \\
\hline & $6-7$ & $28(11.6)$ & & & \\
\hline & $8-10$ & $117(73.1)$ & & & \\
\hline \multirow{3}{*}{ 6. Children get more shots than are good for them. } & I agree & $50(20.7)$ & & \multirow{3}{*}{0.60} & \\
\hline & I Disagree & $118(48.8)$ & & & \\
\hline & I'm not sure. & $74(30.6)$ & & & \\
\hline \multirow{3}{*}{$\begin{array}{l}\text { 7. I believe that many of the illnesses that shots } \\
\text { prevent are severe. }\end{array}$} & I agree & $196(81.0)$ & & \multirow{3}{*}{0.39} & \\
\hline & I disagree & $22(9.1)$ & & & \\
\hline & I'm not sure. & $24(9.9)$ & & & \\
\hline \multirow{3}{*}{$\begin{array}{l}\text { 8. It is better for my child to develop immunity by } \\
\text { getting sick than to get a shot. }\end{array}$} & I agree & $57(23.6)$ & & \multirow{3}{*}{0.46} & \\
\hline & I disagree & $124(51.2)$ & & & \\
\hline & I'm not sure. & $61(25.2)$ & & & \\
\hline \multirow{3}{*}{$\begin{array}{l}\text { 9. It is better for children to get fewer vaccines at the } \\
\text { same time. }\end{array}$} & I agree & $100(41.3)$ & \multirow{3}{*}{0.35} & & \\
\hline & I disagree & $52(21.5)$ & & & \\
\hline & I'm not sure. & $90(37.2)$ & & & \\
\hline \multirow{3}{*}{$\begin{array}{l}\text { 10. How concerned are you that your child might have a } \\
\text { serious side effect from a shot? }\end{array}$} & I am worried & $119(49.2)$ & \multirow{3}{*}{0.42} & & \\
\hline & I am not worried & $84(34.7)$ & & & \\
\hline & I'm not sure. & $39(16.1)$ & & & \\
\hline \multirow{3}{*}{$\begin{array}{l}\text { 11. How concerned are you that anyone of the } \\
\text { childhood shots might not be safe? }\end{array}$} & I am worried & $73(30.2)$ & \multirow{3}{*}{0.78} & & \\
\hline & I am not worried & $122(50.4)$ & & & \\
\hline & I'm not sure. & 47 (19.4) & & & \\
\hline \multirow{3}{*}{$\begin{array}{l}\text { 12. How concerned are you that a shot might not } \\
\text { prevent the disease? }\end{array}$} & I am worried & $70(28.9)$ & \multirow{3}{*}{0.68} & & \\
\hline & I am not worried & $123(50.8)$ & & & \\
\hline & I'm not sure. & $49(20.2)$ & & & \\
\hline \multirow{3}{*}{$\begin{array}{l}\text { 13. If you had another infant today, would you want } \\
\text { him/her to get all the recommended shots? }\end{array}$} & Yes & $201(83.1)$ & & \multirow[t]{3}{*}{0.82} & \\
\hline & No & $11(4.5)$ & & & \\
\hline & Don't know & $30(12.4)$ & & & \\
\hline
\end{tabular}




\begin{tabular}{|c|c|c|c|}
\hline \multirow{3}{*}{$\begin{array}{l}\text { 14. Overall, how hesitant about childhood shots would } \\
\text { you consider yourself to be? }\end{array}$} & I am hesitant & $68(28.1)$ & \multirow{3}{*}{0.85} \\
\hline & I am not hesitant & $148(61.2)$ & \\
\hline & I'm not sure. & $26(10.7)$ & \\
\hline \multirow{3}{*}{ 15. I trust the information I receive about shots. } & I agree & $170(70.2)$ & \multirow{3}{*}{0.83} \\
\hline & I disagree & $20(8.3)$ & \\
\hline & I'm not sure. & $52(21.5)$ & \\
\hline \multirow{3}{*}{$\begin{array}{l}\text { 16. I am able to openly discuss my concerns about } \\
\text { shots with my child's doctor. }\end{array}$} & I agree & $180(74.4)$ & \multirow{3}{*}{0.64} \\
\hline & I disagree & 32 (13.2) & \\
\hline & I'm not sure. & $30(12.4)$ & \\
\hline \multirow{3}{*}{$\begin{array}{l}\text { 17. All things considered, how much do you trust your } \\
\text { child's doctor? }\end{array}$} & $0-5^{* *}$ & $28(11.6)$ & \multirow{3}{*}{0.52} \\
\hline & $6-7$ & $44(18.2)$ & \\
\hline & $8-10$ & $170(70.2)$ & \\
\hline
\end{tabular}

Table V. Reliability of scale scores

\begin{tabular}{|l|l|l|l|}
\hline & $\begin{array}{l}\text { Number of } \\
\text { items }\end{array}$ & $\begin{array}{l}\text { Cronbach's } \\
\text { alpha }\end{array}$ & $\begin{array}{l}\text { McDonald's } \\
\text { omega }\end{array}$ \\
\hline $\begin{array}{l}\text { Safety \& } \\
\text { effectiveness }\end{array}$ & 5 & 0.70 & 0.72 \\
\hline General attitudes & 8 & 0.77 & 0.79 \\
\hline Behavior & 2 & 0.61 & 0.63 \\
\hline Total & 15 & 0.84 & 0.85 \\
\hline
\end{tabular}

to be $33 \%$; in another study conducted in Italy, this rate was $34.7 \%$; and in another study conducted in Iraq, it was found to be $20.9 \%$. The change in the proportion of hesitation in different countries may arise due to the contextual or group effects based on cultural differences (4).

\section{Study Limitations}

The sample group of the study was formed by people of relatively higher levels of income and education. This situation should be considered as a limitation of this study in assessing vaccine hesitation rates in the general population. It is recommended to carry out studies in larger samples by paying attention to provincial, district and socio-demographic distributions. Furthermore, there is a need for studies in which the correlation is assessed with another measurement tool of vaccine hesitation.

\section{Conclusion}

The three-factor structure of the PACV scale was adapted into the Turkish language in a reliable and valid way. This adapted scale is suitable for the determination of vaccine hesitations. It will also be a proper tool to compare national results with international findings.

\section{Ethics}

Ethics Committee Approval: Ethics Committee approval was given to the study at the $102^{\text {nd }}$ meeting held by Istanbul Okan University Ethics Committee on 09.01.2019 (decision no: 11).

Informed Consent: Written consent forms were taken from each participant.

Peer-review: Enternally peer-reviewed.

\section{Authorship Contributions}

Surgical and Medical Practices: D.A., Concept: M.A.B., Design: M.A.B., Data Collection or Processing: D.A., Analysis or Interpretation: E.D.H., Ö.G., Literature Search: D.A., Writing: D.A.

Conflict of Interest: None of the authors had conflict of interest.

Financial Disclosure: The authors declared that this study received no financial support.

\section{References}

1. Dubé E, Vivion M, MacDonald NE. Vaccine hesitancy, vaccine refusal and the anti-vaccine movement: Influence, impact and implications. Expert Rev Vaccines 2015; 14:99-117.

2. Lane S, MacDonald NE, Marti M, Dumolard L. Vaccine hesitancy around the globe: Analysis of three years of WHO/UNICEF Joint Reporting Form data-2015-2017. Vaccine [Internet] 2018; 36:3861-7.

3. Domek GJ, O'Leary ST, Bull S, et al. Measuring vaccine hesitancy: Field testing the WHO SAGE Working Group on Vaccine Hesitancy survey tool in Guatemala. Vaccine [Internet] 2018; 36:5273-81.

4. World Health Organization (WHO). Report of the SAGE working group on vaccine hesitancy [Internet], 2014.

5. Opel D), Catz S, Wiese C, et al. Development of a survey to identify vaccine-hesitant parents. Hum Vaccin 2011; 7:419-25. 
6. Hagood EA, Herlihy SM. Addressing heterogeneous parental concerns about vaccination with a multiple-source model: $A$ parent and educator perspective. Hum Vaccines Immunother 2013; 9:1790-4.

7. Leach M, Fairhead J. Vaccine Anxieties Global Science, Child Health \& Society. London: Earthscan 2007; 16-45.

8. Dubé E, Bettinger J, Fisher W, Naus M, Mahmud S, Hilderman T. Vaccine acceptance, hesitancy and refusal in Canada: Challenges and potential approaches. Canada Commun Dis Rep 2016; 42:246-51.

9. Dubé E, Laberge C, Guay M, Bramadat P RR\& JAB. Vaccine hesitancy. Hum Vaccin Immunother 2013; 9:1763-73.

10. Larson HJ, Jarrett C, Eckersberger E, Smith DMD, Paterson $P$. Understanding vaccine hesitancy around vaccines and vaccination from a global perspective: A systematic review of published literature, 2007-2012. Vaccine [Internet] 2014; 32:2150-9.

11. Taddio A. Setting the stage for improved practices during vaccine injections: A knowledge synthesis of interventions for the management of pain and fear. Clin J Pain 2015; 31:1-2.

12. Çapanoğlu E. Sağlık çalışanı ve ebeveyn perspektifinden çocukluk çağı aşılarinin reddi niteliksel bir araştırma [dissertation]. Acıbadem Mehmet Ali Aydınlar Üniversitesi; 2018.

13. Jarrett C, Wilson $\mathrm{R}$, Larson $\mathrm{H}$ ), et al. Measuring vaccine hesitancy: The development of a survey tool. Vaccine 2015; 33:4165-75.

14. Allred NJ, Rickert DL, Santibanez TA, Santoli JM, Shaw KM. Parental vaccine safety concerns Results from the National Immunization Survey, 2001-2002. Am I Prev Med 2005; 28:2214.

15. Freed GL, Clark S), Butchart AT, Singer DC, Davis MM. Parental Vaccine Safety Concerns in 2009. Pediatrics 2010; 125:654-9.

16. Luthy KE, Beckstrand RL, Callister LC. Parental hesitation in immunizing children in Utah. Public Health Nurs 2010; 27:25-31.

17. Bakhache P, Rodrigo C, Davie S, Ahuja A, Sudovar B, Rose M, et al. Health care providers' and parents' attitudes toward administration of new infant vaccines-a multinational survey. Eur | Pediatr 2012; 172:485-92

18. My C, Danchin M, Willaby HW, Pemberton S, Leask J. Parental attitudes, beliefs, behaviours and concerns towards childhood vaccinations in Australia: A national online survey. Aust Fam Physician 2017; 46:145-51.
19. Greenberg J, Dubé E, Driedger M. Vaccine Hesitancy: In Search of the Risk Communication Comfort Zone. PLoS Curr [Internet] 2017; 9.

20. Opel DJ, Taylor JA, Mangione-Smith R, et al. Validity and reliability of a survey to identify vaccine-hesitant parents. Vaccine [Internet] 2011; 29:6598-605.

21. Roberts $/ R$, Thompson D, Rogacki B, et al. Vaccine hesitancy among parents of adolescents and its association with vaccine uptake. Vaccine [Internet] 2015; 33:1748-55.

22. Correa A, Munoz FM, Kerr GB, et al. Development of a Spanish version of the parent attitudes about childhood vaccines survey. Hum Vaccin Immunother [Internet] 2019; 0:1-24.

23. Raof AM. Parental attitude and beliefs towards child vaccination: identifying vaccine hesitant groups in a family health center, Erbil city, Iraq. World Fam Med 2018; 16:17-26.

24. Mohd Azizi FS, Kew Y, Moy FM. Vaccine hesitancy among parents in a multi-ethnic country, Malaysia. Vaccine [Internet] 2017; 35:2955-61.

25. Strelitz B, Gritton J, Klein E), et al. Parental vaccine hesitancy and acceptance of seasonal influenza vaccine in the pediatric emergency department. Vaccine [Internet] 2015; 33:1802-7.

26. Napolitano F, D'Alessandro A, Angelillo IF. Investigating Italian parents' vaccine hesitancy: A cross-sectional survey. Hum Vaccines Immunother [Internet] 2018; 14:1558-65.

27. Dubé Ė, Farrands A, Lemaitre $T$, et al. Overview of knowledge, attitudes, beliefs, vaccine hesitancy and vaccine acceptance among mothers of infants in Quebec, Canada. Hum Vaccin Immunother [Internet] 2019; 15:113-20.

28. Opel DJ, Taylor JA, Zhou C, Catz S, Myaing M, Mangione-Smith R. The Relationship Between Parent Attitudes About Childhood Vaccines Survey Scores and Future Child Immunization Status: A Validation Study. JAMA Pediatr 2013; 167:1065-71.

29. Beaton DE, Bombardier C, Guillemin F, Ferraz MB. Guidelines for the Process of Cross-Cultural Adaptation of Self-Report Measures. Spine (Phila Pa 1976) [Internet] 2000; 25:3186-91.

30. Gilkey $M B$, McRee $A L$, Magnus $B E$, Reiter $P L$, Dempsey $A F$, Brewer NT. Vaccination confidence and parental refusal/delay of early childhood vaccines. PLoS One. 2016; 11:1-12. 